\title{
Relato de uma Experiência de Auxílio Personalizado a Alunos em Ambiente Virtual de Aprendizagem Utilizando Agentes
}

\author{
Vitor Bremgartner, José Francisco M. Netto \\ Instituto de Computação (IC/PPGI) - Universidade Federal do Amazonas (UFAM) \\ Av. Gen. Rodrigo Otávio, Coroado. Manaus - AM - Brasil \\ \{vitorbref, jnetto\} @icomp.ufam.edu.br
}

\begin{abstract}
This paper describes a blended learning experiment in Numerical Analysis discipline of Mathematics undergraduate degree course at Federal University of Amazonas (UFAM). We present some of the central elements of the proposal, which deals with assistance to students with doubts in the Virtual Learning Environment (VLE) used through the use of software agents. Such aid is a personalized recommendation of colleagues able to help depending on their skills and competencies. The results show the feasibility of the proposal and indicate future directions of research.
\end{abstract}

Resumo. Este artigo descreve uma experiência com a oferta na modalidade semipresencial da disciplina Cálculo Numérico no curso de graduação em Matemática na Universidade Federal do Amazonas (UFAM). São apresentados alguns dos elementos centrais da proposta, que trata do auxílio a alunos com dúvidas no Ambiente Virtual de Aprendizagem (AVA) utilizado, por meio da utilização de agentes de software. Tal auxílio é a recomendação personalizada de colegas aptos para ajudar em função de suas habilidades $e$ competências. Os resultados obtidos mostram a viabilidade da proposta e apontam direcionamentos futuros da pesquisa.

\section{Introdução}

Este trabalho apresenta uma experiência realizada em uma disciplina semipresencial de Cálculo Numérico aplicada ao curso de Matemática na Universidade Federal do Amazonas (UFAM). Os testes foram realizados no Ambiente Virtual de Aprendizagem (AVA) mais utilizado no mundo atualmente, o Moodle [Moodle, 2012] no suporte a ações semipresenciais ou à distância e que incorpora características importantes, especialmente no que se refere ao trabalho, gerenciamento e percepção de grupos no ambiente (awareness). Quanto ao uso deste AVA, por exemplo, somente no ano de 2011, diversos trabalhos realizaram experimentos nesta ferramenta, onde alguns são [Albernaz et al, 2011] [Barin et al, 2011].

Neste trabalho, o AVA é executado em conjunto com um Sistema Multiagente (SMA) de apoio às dúvidas que os alunos têm sobre determinado assunto na disciplina. Em se tratando de agentes de software, esta tecnologia representa um paradigma para desenvolvimento de aplicações computacionais, de tal forma que sua utilização tem acontecido nos mais variados tipos de aplicações. Segundo Wooldridge, "agentes são 
sistemas computacionais capazes de ações autônomas em algum ambiente, a fim de alcançarem seus objetivos de projeto" [Wooldridge, 2009].

Para melhor entendimento do sistema multiagente usado como sistema de apoio ao AVA, consideremos um grupo de alunos participantes de um curso de Educação à Distância $(\mathrm{EaD})$ ou semipresencial. No AVA, há professores e tutores monitorando o curso, entretanto não há um gerenciamento de forma automática e eficaz com relação ao acompanhamento das dúvidas e de seus esclarecimentos que os alunos possuem sobre um determinado assunto, que também podem ser evidenciadas se uma tarefa não for entregue até a data estipulada para sua entrega.

Para solucionar este problema, uma camada de inteligência formada por um sistema multiagente foi acoplada ao ambiente educacional, utilizando uma ontologia que descreve o modelo de aluno para auxiliar as atividades dos alunos pela indicação personalizada de algum estudante do mesmo curso. A personalização aplicada ao AVA é a busca por um ou mais estudantes com perfil adequado, isto é, estudantes que possuam habilidades e competências desejáveis para tratar de dúvidas sobre determinado assunto das questões de alunos [Bremgartner e Netto, 2011a]. A proposta foi baseada na ideia de que a interação entre aprendizes é uma estratégia empregada com o propósito de construir conhecimento de maneira mais significativa. Isto ocorre porque os aprendizes desenvolvem habilidades intra e interpessoais, deixam de ser independentes para serem interdependentes [Okada, 2003].

Além desta seção de introdução, este artigo está estruturado da seguinte forma: a seção 2 descreve a visão geral do SMA que é executado em conjunto ao AVA, bem como é descrito o processo de recomendação de estudantes; a seção 3 apresenta resultados e discussões sobre os testes realizados no sistema com uma turma simulada e depois uma turma real de Cálculo Numérico; e a seção 4 faz as conclusões e propostas para trabalhos futuros.

\section{Visão Geral do Sistema}

Uma visão geral do sistema é apresentada na Figura 1. O professor elabora e solicita as atividades (a. Prepara atividades). Para este trabalho, no Moodle foi acrescentado um recurso ao se criar uma nova atividade, permitindo associar competências e habilidades necessárias com as atividades propostas. $\mathrm{O}$ professor, ao solicitar uma atividade no ambiente, especifica quais competências e habilidades são necessárias para a execução da atividade. O estudante, por sua vez, interage com o sistema, seja pelo cadastro de seus dados pessoais, pela postagem de algo no fórum ou resolução de atividades propostas no ambiente, onde dúvidas podem surgir (b. Faz atividades e tem dúvidas). Paralelamente, à medida que os estudantes vão interagindo com o ambiente, seus modelos de aluno são atualizados no banco de dados do Moodle pelo sistema multiagente composto de sete agentes desenvolvidos no framework JADE [JADE, 2012], sendo o SMA também responsável, juntamente com a ontologia desenvolvida no editor Protégé [Protégé, 2012], por procurar os estudantes com melhores níveis de competências e habilidades específicas capazes de ajudar aquele aluno que estiver com dúvidas em atividades (c. Manipular ações dos usuários). Dessa forma, os estudantes com perfis adequados encontrados pelo sistema multiagente para ajudar serão 
recomendados no Moodle para aquele aluno que tem dúvidas (d. Recomendações). As setas tracejadas mostram a sequência deste processo de recomendação.

Este sistema contém três agentes de atualização, que são responsáveis por alterar os dados do aluno. O primeiro deles é o Initial Skills Agent, que configura os níveis de habilidades e competências iniciais dos alunos (ajustados pelo professor) e envia estas informações ao Update Profile Agent, que é o responsável por atualizar os dados dos modelos de alunos mediante as interações dos mesmos com o ambiente. Outro agente é o Activity Assessment Agent, responsável pela avaliação das questões respondidas, e envia as pontuações dos alunos ao Update Profile Agent.

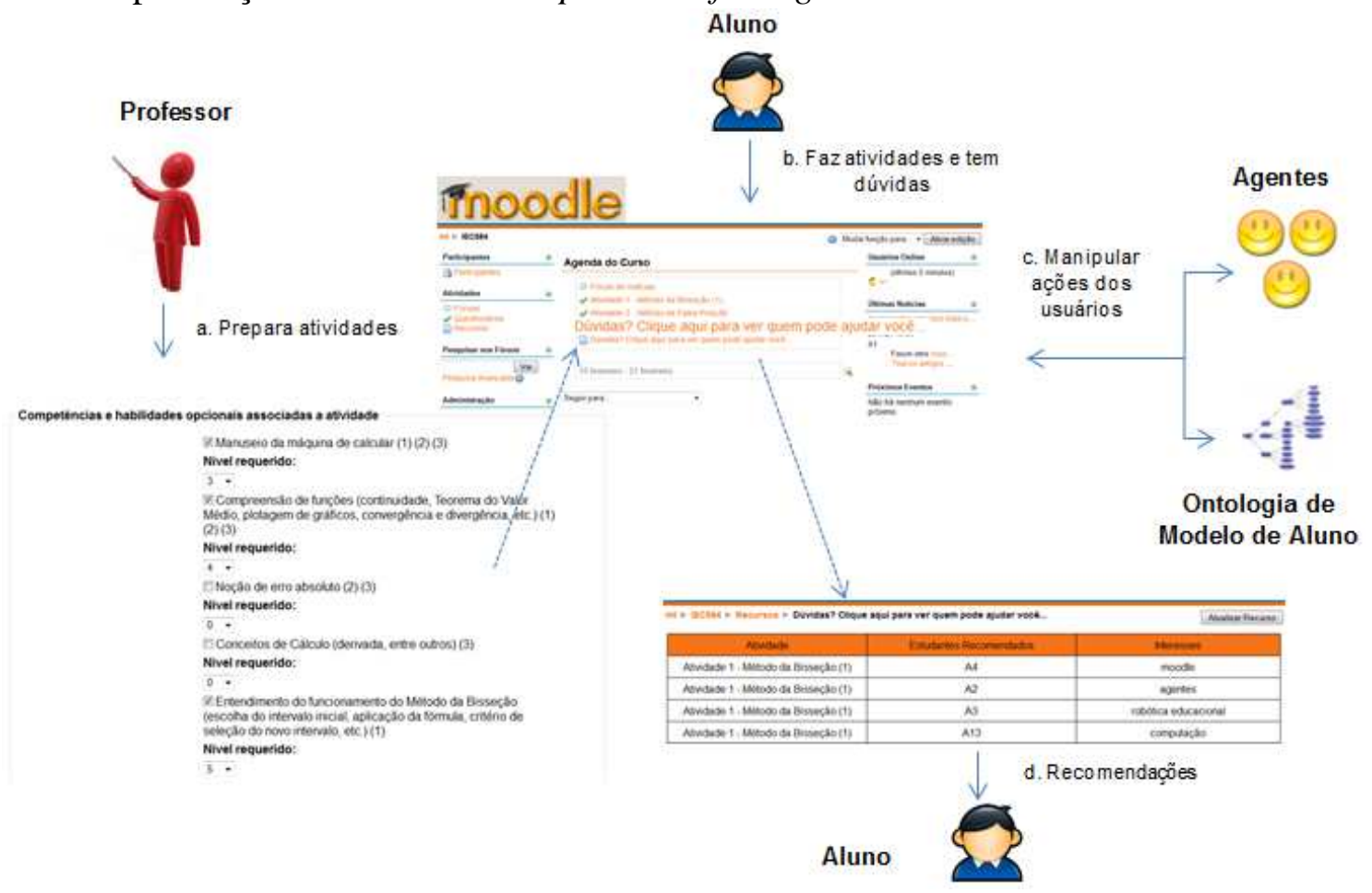

Figura 1. Visão Geral do Sistema.

Existem dois agentes de recomendação responsáveis pelo processo de recomendação de alunos que podem ajudar seus colegas. O primeiro é o Doubt \& Error Profile Agent, que faz a busca por dúvidas e erros dos alunos com base nos resultados das questões respondidas no ambiente e que mapeia tais erros em habilidades e competências necessárias para a realização das tarefas. Com estas informações, este agente envia uma mensagem ao Recommended Profile Agent dados da existência de alunos com dúvidas e erros, e este, por sua vez, busca por alunos com níveis de habilidades e competências específicas (maiores ou iguais às sugeridas pelo professor no cadastro de novas atividades, que variam numa faixa de 0 a 10) capazes de resolver as questões propostas. Os dados de recomendações de alunos selecionados pelo Recommended Profile Agent são salvos no banco de dados do Moodle para depois serem listados aos alunos com erros ou dúvidas relativos à atividade proposta.

Por fim, os dois agentes de tutoria que enviam mensagens aos alunos no AVA, são o Notifier Activity Agent, que informa aos estudantes as novas atividades solicitadas pelo professor, e o Help Tutor Agent, responsável por enviar dois tipos de mensagens. $\mathrm{O}$ primeiro tipo consiste em mensagens para os alunos com dúvidas, enviando um link que 
eles podem acessar para ver seus colegas recomendados. O segundo tipo de mensagens é para aqueles alunos que não entregaram a tarefa no prazo estabelecido pelo professor.

Por convenção, cada competência do aluno neste trabalho é constituída por uma ou mais habilidades, pois não há uma definição precisa e única destes termos na literatura [Perrenoud, 1999]. As competências e habilidades do aluno fazem parte da ontologia que descreve o modelo do mesmo e esta foi integrada aos agentes [Bremgartner e Netto, 2011b]. A ontologia também é útil para a correta manipulação das trocas de mensagens entre agentes, cuja comunicação entre agentes segue o padrão FIPA-ACL (Agent Communication Language) [FIPA, 2012].

\section{Experimentos Realizados na Disciplina de Cálculo Numérico}

Nesta seção serão apresentados a avaliação e os testes realizados do sistema. Na pesquisa, foi utilizada um Personal Computer (PC), para fazer o papel do servidor web e programas de computador open-source disponíveis na Internet, tais como o pacote XAMPP versão 1.7.3 para Sistema Operacional Windows (32 bits), que contém o servidor web Apache versão 2.2.14, o banco de dados MySQL versão 5.1.41 e o servidor de páginas para a web PHP versão 5.3.1, o ambiente Moodle versão 1.9.6, o JADE versão 3.7 e o JAVA para que os agentes JADE fossem desenvolvidos e executados juntamente com o AVA.

Os testes foram divididos em duas etapas: um teste em uma turma fictícia da disciplina de Cálculo Numérico, ou seja, foi realizada uma simulação do sistema a fim de avaliar o desempenho dos agentes que usam a ontologia de modelo do aluno integrados ao AVA Moodle e um segundo teste, constituindo-se do uso dos agentes e da ontologia no ambiente em uma turma real de Cálculo Numérico do curso de Matemática da Universidade Federal do Amazonas (UFAM).

\subsection{Simulações em Turma Fictícia}

Foram realizados testes de nosso sistema com uma turma simulada de Cálculo Numérico no Moodle contendo 15 alunos que possuem diferentes perfis. O AVA esteve disponível no servidor do Laboratório de Robótica Educacional da UFAM.

Maiores detalhes dos testes simulados podem ser vistos em [Bremgartner e Netto, 2011a], porém é importante citar aqui que foram realizadas simulações antes da aplicação em uma turma real para ser verificada a eficiência do uso dos agentes e da ontologia no recurso de recomendação de estudantes no Moodle. Dependendo do resultado das simulações, os testes poderiam ou não ser aplicados em uma turma real.

Foram elaboradas duas atividades envolvendo assuntos de Método da Bisseção e uma atividade envolvendo o Método da Falsa Posição. Nas atividades de Método da Bisseção, cuja competência envolvida é "Achar as raízes de funções pelo método da Bisseção", os níveis de habilidades requeridos escolhidos pelo professor para as habilidades "Manuseio da máquina de calcular", "Compreensão de funções" e "Entendimento do método da bisseção" foram, respectivamente, 3, 4, e 5. Na atividade sobre o Método da Falsa Posição, cuja competência envolvida é "Achar as raízes de funções pelo método da Falsa Posição", as habilidades requeridas que têm o mesmo nome das duas atividades anteriores tiveram os mesmos níveis destas e as habilidades 
"Noção de erro absoluto" e "Entendimento do funcionamento do método da falsa posição" tiveram, respectivamente, 4 e 5 .

Todos os 15 alunos fictícios receberam a notificação de novas atividades, antes de responderem as mesmas, pelo Notifier Activity Agent, como mostra a Figura 2. Cada estudante com dúvida em atividades recebeu uma mensagem do Help Tutor Agent indicando que eles poderiam tirar dúvidas com seus colegas, clicando no link de recomendação. Quando o estudante com dúvida clica neste link aparece a tela de recomendação, com os alunos recomendados para cada atividade e seus interesses, a fim de que os alunos saibam que outras áreas de interesse seus colegas costumam atuar, como pode ser visto na Figura 1, mostrada na seção 2. O Help Tutor Agent também notificou todos os alunos que não entregaram as tarefas na data limite, enviando mensagem via Moodle.

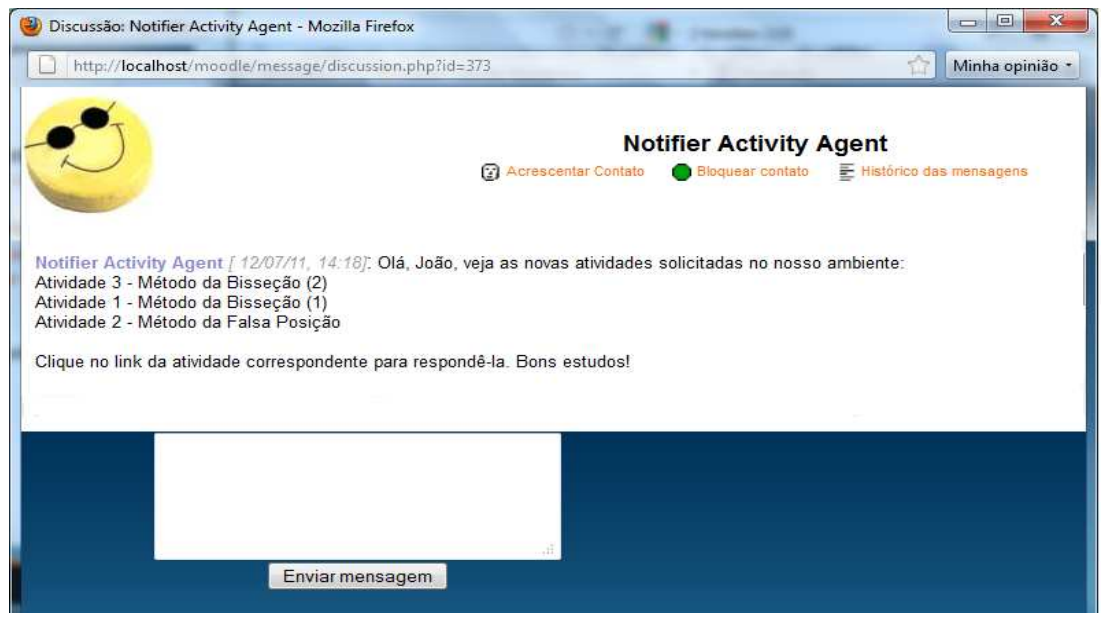

Figura 2. Mensagem de notificação de novas atividades aos alunos.

Percebeu-se ao fim dos testes simulados que os níveis de competências e habilidades dos alunos foram incrementados de uma unidade para cada questão correta, enquanto houve um decréscimo de uma unidade para cada uma das atividades erradas.

Nas simulações realizadas, obtivemos sucesso quanto às atualizações do modelo de aluno de acordo com as interações dos estudantes no AVA e que os alunos com níveis de habilidades maiores ou iguais às solicitadas pelo professor na elaboração de atividades foram os alunos recomendados a sanar dúvidas de outros colegas no Moodle.

\subsection{Testes em Turma Real}

Após os resultados satisfatórios obtidos com o teste em uma turma fictícia, foi a vez de avaliar a eficácia do sistema em uma turma real composta por 33 alunos da disciplina de Cálculo Numérico do curso de Matemática do período letivo 2011/02 da UFAM, ministrada de forma presencial, porém as atividades para testes do sistema foram passadas pelo ambiente Moodle. A Figura 3 mostra o ambiente usado pela turma. 


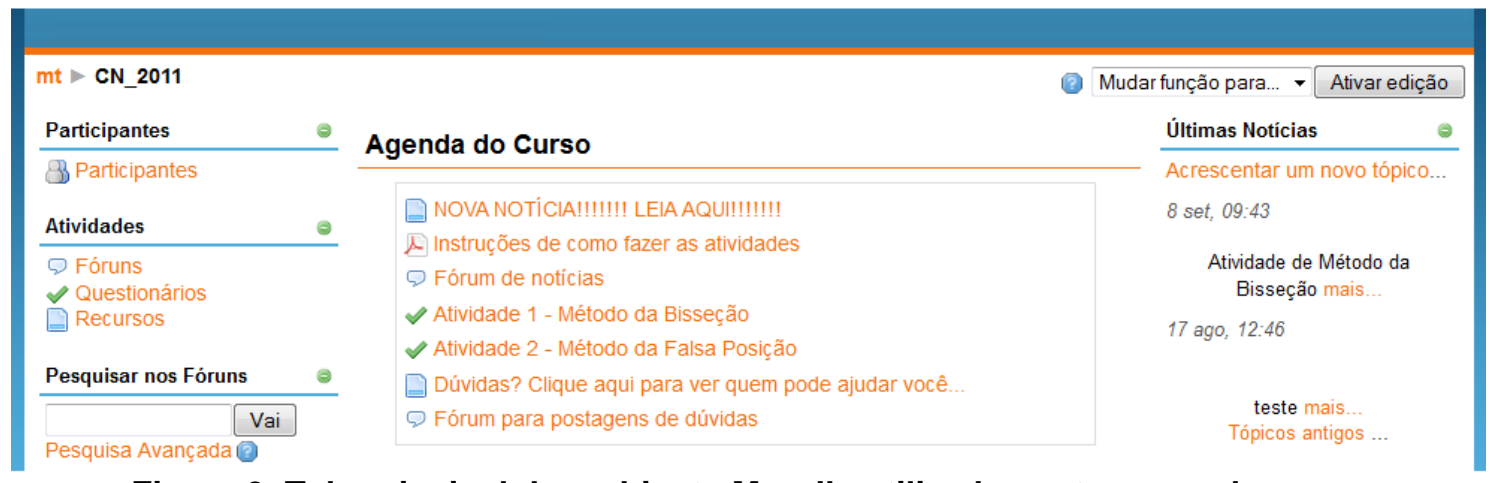

Figura 3. Tela principal do ambiente Moodle utilizado em turma real.

Como pode ser visto na Figura 3, os alunos tinham acesso a um arquivo explicativo no formato PDF sobre como os alunos deveriam fazer as atividades no ambiente. No AVA estavam também alguns links de notícias, fórum para postagens de dúvidas e o link de recomendação, para mostrar quem são os alunos que poderiam auxiliar no caso de dúvidas ou erros em atividades. Para a turma real foram passadas duas atividades: uma envolvendo o método da bisseção e outro envolvendo o método da falsa posição. $\mathrm{O}$ formato das atividades passadas aos alunos é apresentado na Figura 4. Neste caso, há um exemplo de método da bisseção respondido.

\section{Atividade 1 - Método da Bisseção - Tentativa 1}

Encontre uma raiz real para $f(x)=a x^{\wedge} 3+b x^{\wedge} 2+c x+d$.

Defina os coeficientes abaixo, e em seguida, os valores para xD (à direita) e xE (à esquerda), na primeira linha da tabela. Em seguida, calcule o xM (médio) e complete o restante da tabela até chegar em uma raiz da função.

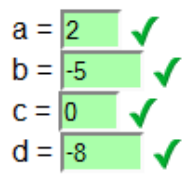

Considerar:

A tolerância $\mathrm{Tol}=0.0100$;

4 casas decimais nos valores (p. ex, $3.0000,5.1254)$.

\begin{tabular}{|c|c|c|c|c|c|c|c|c|c|c|c|c|}
\hline Interação & \multicolumn{2}{|c|}{$x E$} & \multicolumn{2}{|c|}{$x D$} & \multicolumn{2}{|c|}{$\mathrm{xM}$} & \multicolumn{2}{|c|}{$f(x E)$} & \multicolumn{2}{|c|}{$f(x D)$} & \multicolumn{2}{|c|}{$f(x M)$} \\
\hline 1) & 2.9000 & $\sqrt{ }$ & 3.0000 & $\sqrt{ }$ & 2.9500 & $\sqrt{ }$ & $\mid-1.2720$ & $\sqrt{ }$ & 1.0000 & $\sqrt{ }$ & $\mid-0.1677$ & $\sqrt{ }$ \\
\hline 2) & 2.9500 & $\sqrt{ }$ & 2.9750 & $\sqrt{ }$ & 2.9625 & $\sqrt{ }$ & $\mid-0.1677$ & $\sqrt{ }$ & 0.4081 & $\sqrt{ }$ & 0.1182 & $\sqrt{ }$ \\
\hline 3) & 2.9563 & $\sqrt{ }$ & 2.9625 & $\sqrt{ }$ & 2.9594 & $\sqrt{ }$ & -0.0253 & $\sqrt{ }$ & 0.1182 & $\sqrt{ }$ & 0.0463 & $\sqrt{ }$ \\
\hline 4) & 2.9563 & $\sqrt{ }$ & 2.9578 & $\checkmark$ & 2.9570 & $\sqrt{ }$ & -0.0253 & $\checkmark$ & 0.0105 & $\sqrt{ }$ & -0.0074 & $\sqrt{ }$ \\
\hline 5) & 2.9570 & $\sqrt{ }$ & 2.9574 & $\sqrt{ }$ & 2.9572 & $\checkmark$ & $\mid-0.0074$ & $\checkmark$ & 0.0015 & $\sqrt{ }$ & -0.0029 & $\sqrt{ }$ \\
\hline
\end{tabular}

Enviar

Figura 4. Exemplo de uma atividade respondida.

O teste em turma real foi dividido em duas partes menores. A primeira parte foi disponibilizar o AVA na Web para que os alunos fizessem as atividades em um período de tempo pré-estabelecido, com os agentes sendo executados em conjunto com o Moodle a fim de tornar o ambiente mais adaptável aos estudantes pela recomendação de colegas para auxiliar os alunos com dúvidas. A segunda parte consistiu em avaliar e 
verificar o processo de interação com os alunos após a recomendação de alunos auxiliares da mesma turma, verificando ainda se os alunos que erraram na primeira parte, após o contato com seus colegas que podem auxiliá-los, acertaram ao fazerem os exercícios de Cálculo Numérico pela segunda vez. A execução das tarefas dos agentes nestas duas etapas ocorreu do mesmo modo que no processo de teste simulado.

Ao final de cada parte dos testes reais foi passado um questionário de pesquisa de opinião a fim de que os alunos expressassem suas ideias a respeito do sistema apresentado a eles. O questionário que foi passado aos alunos ao término da primeira fase dos testes, com seus resultados obtidos, está apresentado na Tabela 1.

Tabela 1. Primeiro questionário de pesquisa de opinião passado à turma de Cálculo Numérico.

\begin{tabular}{|c|l|c|}
\hline Questão & \multicolumn{1}{|c|}{ Pergunta } & Resultados Obtidos \\
\hline 1 & $\begin{array}{l}\text { Você conseguiu fazer o exercício postado no } \\
\text { Ambiente Moodle? }\end{array}$ & SIM - 70\%; NÃO - 30\% \\
\hline 2 & $\begin{array}{l}\text { Você sentiu a interface amigável ao executar o } \\
\text { exercício ou até mesmo o Moodle? }\end{array}$ & SIM - 79\%; NÃO - 21\% \\
\hline 3 & $\begin{array}{l}\text { Com que frequência ou em que horários fez o } \\
\text { exercício proposto? }\end{array}$ & $\begin{array}{c}\text { NOITE - 35\%; MANHÃ - 5\%; } \\
\text { TARDE - 30\%; NUNCA - 30\% }\end{array}$ \\
\hline 4 & $\begin{array}{l}\text { Sentiu alguma dificuldade ou dúvida ao fazer os } \\
\text { exercícios? Qual(is)? }\end{array}$ & SIM - 50\%; NÃO - 50\% $(*)$ \\
\hline $\begin{array}{l}(*) \text { As principais dificuldades que os alunos apontaram foi de não escolher os valores corretos para que } \\
\text { o método funcione e que eles precisavam de mais interações, ou seja, eles não conseguiam chegar pelo } \\
\text { menos até a tolerância }( \pm 0.010) .\end{array}$ \\
\hline
\end{tabular}

Quanto aos comentários que os alunos fizeram, os principais (contendo elogios, críticas e sugestões) foram: "Parabéns, bem elaboradas (as atividades)"; "Dificuldade de acesso (alguns alunos tiveram dificuldade em acessar o site)"; "É muito bom poder fazer os exercícios assim"; "Estão de parabéns"; "Atividades compreensíveis"; "O site deveria ficar mais tempo disponível (devido ao intervalo de tempo em que as atividades estavam disponíveis)"; "Bastante simples (o site)". É interessante ressaltar que um aluno acessou o Moodle pelo celular, o que possibilitou novas ideias de aprimoramentos futuros no sistema, como adaptação do ambiente ao dispositivo móvel que o usuário utilizar.

Percebe-se pela Tabela 1 que existiram alunos que não fizeram as atividades. Com isso, muitos alunos foram alertados do atraso de suas atividades pelos agentes de tutoria. Apenas dois alunos acertaram as questões nesta primeira parte dos testes, que foram os recomendados pelos agentes de recomendação a auxiliarem seus colegas. Após a segunda parte de testes reais foi passado o segundo questionário, onde as perguntas e os resultados obtidos estão apresentados na Tabela 2.

Tabela 2. Segundo questionário passado à turma de Cálculo Numérico.

\begin{tabular}{|c|l|c|}
\hline Questão & \multicolumn{1}{|c|}{ Pergunta } & \multicolumn{1}{|c|}{ Resultados Obtidos } \\
\hline 1 & $\begin{array}{l}\text { Você conseguiu fazer o exercício postado no } \\
\text { Ambiente Moodle após a recomendação dos } \\
\text { estudantes para lhe ajudar a resolver as atividades? }\end{array}$ & \multicolumn{1}{|c|}{ SIM - 90\%; NÃO - 10\% } \\
& $\begin{array}{l}\text { Caso você seja um aluno recomendado, descreva } \\
\text { apenas como você fez o exercício de tal forma que } \\
\text { obteve o acerto. }\end{array}$ & \\
\hline
\end{tabular}




\begin{tabular}{|c|c|c|}
\hline 2 & $\begin{array}{l}\text { Descreva o processo de interação que você teve } \\
\text { com o aluno recomendado ou com os alunos que lhe } \\
\text { procuraram, visto que você pode ter sido o } \\
\text { recomendado. Indique se você foi o aluno } \\
\text { recomendado ou não. }\end{array}$ & $\begin{array}{l}\text { Os principais comentários serão } \\
\text { relatados a seguir, fora desta } \\
\text { tabela. }\end{array}$ \\
\hline 3 & $\begin{array}{l}\text { Você achou o manual de como fazer os exercícios } \\
\text { fácil de entender? }\end{array}$ & $\begin{array}{l}\text { SIM - } 15 \text { alunos; NÃO - } 1 \text { aluno } \\
\text { ("eu não achei o manual"). }\end{array}$ \\
\hline 4 & $\begin{array}{l}\text { O que você achou desta forma de auxílio a colegas } \\
\text { através da recomendação de estudantes a fim de } \\
\text { tirar dúvidas de colegas no contexto desta disciplina } \\
\text { de Cálculo Numérico? }\end{array}$ & $\begin{array}{l}\text { Os principais comentários serão } \\
\text { relatados a seguir, fora desta } \\
\text { tabela. }\end{array}$ \\
\hline 5 & $\begin{array}{l}\text { Você conseguiu visualizar as mensagens de alerta } \\
\text { que chegavam até você via Moodle, como } \\
\text { indicativo de novas atividades, ou indicativo de que } \\
\text { você pode estar com alguma dúvida em atividades, } \\
\text { ou se você até mesmo deixou de fazer alguma } \\
\text { atividade? }\end{array}$ & $\mathrm{SIM}-56 \% ; \mathrm{NÃO}-44 \%(* *)$ \\
\hline 6 & $\begin{array}{l}\text { Espaço para comentários, elogios, críticas, } \\
\text { vantagens e dificuldades a atividade passada no } \\
\text { Moodle. }\end{array}$ & $\begin{array}{l}\text { Os principais comentários serão } \\
\text { relatados a seguir, fora desta } \\
\text { tabela. }\end{array}$ \\
\hline \multicolumn{3}{|c|}{$\begin{array}{l}\text { (*) Alguns comentários relevantes dos alunos que disseram "SIM" foram que ficou mais fácil fazer os } \\
\text { exercícios a partir do recurso das recomendações. Quanto aos dois alunos recomendados, eles disseram } \\
\text { que foi muito prático usar o ambiente, executando as instruções descritas no site e fazendo os exercícios } \\
\text { do mesmo modo que descrito em sala de aula. } \\
\text { (**) Os alunos que não visualizaram as mensagens foram os que conseguiram fazer suas atividades a } \\
\text { tempo e fizeram corretamente ou aqueles que não acessaram o sistema Moodle. }\end{array}$} \\
\hline
\end{tabular}

Quanto à questão 2 da Tabela 2, os principais comentários de como foram as interações no processo de recomendação estão assim descritos: "(...) bem interessante as recomendações, houve mais conhecimento"; "ninguém me procurou e eu não procurei ninguém"; "(..) realizei as atividades sozinho"; "não fui um recomendado, mas os alunos me procuraram pra tirar dúvidas"; "ajudei alguns colegas a entrarem no portal e dei algumas dicas de como resolver os exercícios". Na questão 4, as principais opiniões a respeito desta forma de interação para auxílio de dúvidas aos alunos foram: "É uma ideia boa (...)"; "Achei ótimo"; "Eficaz"; "Muito boa, principalmente os exercícios"; "(...) Bom por ser dinâmico"; "Ótima ideia e recomendaria que outros professores fizessem isso também"; "Acho válida, de muita utilidade, pois eles explicam coisas que o professor às vezes passa batido"; "Muito interessante, aprendizado para ambos"; "mais um meio para tirar dúvidas, um meio de interação". Já na questão 6, a respeito de comentários gerais dos alunos sobre o ambiente, com críticas e sugestões, foram: "Parabéns a todos que estão por trás desse auxílio ao aluno, isso torna a matéria muito mais aplicativa e de bom interesse total"; "O site servia pra dinamizar ainda mais a matéria. O que não deixa o aluno perdido"; "Queria elogiar o espaço Moodle, pois serviu de grande ajuda à aqueles que estavam em dificuldade na matéria (...)"; "A dificuldade maior seria no carregamento da página. Tinha dias que nem a página inicial abria, mas o espaço é bom"; "mudar a interface".

A Figura 5 mostra por meio de gráficos o desempenho dos alunos antes e depois do processo de recomendação, ou seja, nas duas etapas dos testes em turma real. Percebe-se que houve uma melhora por parte dos alunos na resolução de suas atividades, apesar da taxa de erros ainda ser elevada (63\%). Porém, estes erros 
persistiram em decorrência de fatores externos ao sistema, como a ausência/evasão por parte de alguns alunos para refazerem as atividades propostas.

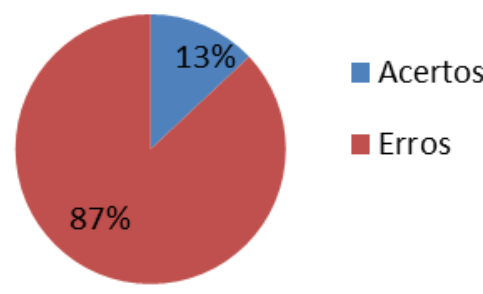

(a)

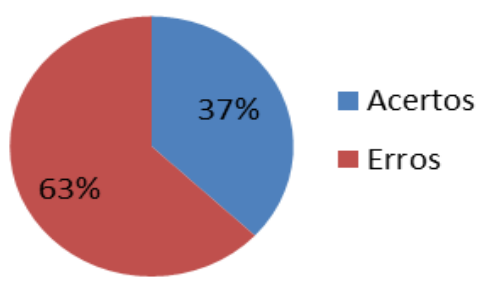

(b)

Figura 5. Gráficos de comparação de desempenho dos alunos (a) antes e (b) depois do processo de recomendação na turma de Cálculo Numérico.

\subsection{Discussões Sobre os Testes}

Os resultados dos testes realizados neste estudo de caso comprovam que o sistema e a estratégia de recomendação de estudantes são viáveis de serem executados em ambientes educacionais reais, como também mostram que o recurso de recomendação personalizada de alunos com perfil adequado para tirar dúvidas de seus colegas aumentou a motivação e promoveu a aprendizagem colaborativa entre estudantes, sendo uma importante estratégia pedagógica, face à utilização do sistema multiagente que utiliza a ontologia baseada em competências e habilidades do aluno, ambos integrados ao AVA Moodle.

Os resultados dos testes aplicados mostraram-se satisfatórios, tanto em sua parte tecnológica, pelas simulações, quanto no uso do sistema por alunos reais, com base nas respostas obtidas pelos alunos através dos questionários passados em sala de aula. Os testes simulados foram necessários, uma vez que eventuais falhas nestes permitiriam identificar problemas que deveriam ser resolvidos antes mesmo do sistema ser executado em uma turma real de estudantes.

Um aspecto importante observado é que o nível de acertos de alunos aumentou na segunda etapa dos testes realizados em turma real (180\%), mesmo muitos terem "evadido" do sistema. Sugere-se que em próximas aplicações em turmas reais, o problema da evasão de alunos possa ser evitado, aplicando-se estratégias de motivação nos alunos.

Conseguiu-se, assim, observar que a interação entre aprendizes incentivados pela integração dos agentes com a ontologia de modelo de aluno no Moodle foi um papel importante para os alunos concluírem as atividades propostas pelo professor com êxito. Esta estratégia utilizada de recomendação veio a ser mais uma forma de auxiliar alunos a concluírem suas atividades, aumentando seus níveis de aprendizado por meio de interações entre si. 


\section{Conclusões e Trabalhos Futuros}

Este artigo apresenta experimentos realizados em um AVA aplicado em uma turma de Cálculo Numérico da UFAM, onde neste ambiente houve uma estratégia de personalização que usa uma ontologia baseada em competências de alunos integrada em um sistema multiagente apto a atualizar, analisar e recomendar estudantes para ajudar os colegas com dúvidas. O processo de recomendação descrito neste artigo aumenta o nível de interação entre estudantes, assim aumentando o nível de conhecimento dos aprendizes como um todo e uma maior corretude das atividades respondidas.

Os testes realizados mostraram que a recomendação de estudantes para auxiliarem outros com dúvidas por meio da aprendizagem colaborativa é uma solução útil e eficaz para o problema do auxílio a alunos com dúvidas em AVAs, melhorando o aprendizado dos alunos. Esta estratégia de auxílio é mais uma forma de aprimorar o ensino de alunos através das modernas Tecnologias de Informação e Comunicação. A abordagem utilizada do SMA aliado à ontologia de modelo de aluno pode ser aplicada a outros AVAs, desde que o SMA e o AVA compartilhem o mesmo banco de dados.

Como trabalhos futuros, pretende-se aprimorar o sistema para adaptação em dispositivos móveis, bem como permitir maior integração do recurso de recomendação em diferentes AVAs, face à portabilidade das tecnologias empregadas.

\section{Referências}

Albernaz, J. M. et al. (2011) "Reflexões sobre um Curso de Jogos Computacionais Livres para o Ensino das Primeiras Noções Matemáticas, em EAD”. In: XVII Workshop de Informática na Escola WIE2011, Aracaju, SE. Anais do XXII SBIE - XVII WIE. Porto Alegre: SBC - Sociedade Brasileira de Computação, p. 1148-1156.

Bremgartner, V. e Netto, J. F. M. (2011) “Auxílio Personalizado a Estudantes em Ambientes Virtuais de Aprendizagem Utilizando Agentes e Competências”. In: XXII Simpósio Brasileiro de Informática na Educação - SBIE2011, Aracaju, SE. Anais do XXII SBIE - XVII WIE. Porto Alegre: SBC Sociedade Brasileira de Computação, p. 40-49.

Bremgartner, V. e Netto, J. F. M. (2011) “An Adaptive Strategy to Help Students in e-Learning Systems Using Competency-Based Ontology and Agents”. Proc. IEEE International Conference on Intelligent Systems Design and Applications - ISDA 2011.

Barin, C. S. et al. (2011) "Programação e monitoramento de atividade de estudo 'Lição' na mediação tecnológico-educacional Moodle”. In: XVII Workshop de Informática na Escola - WIE2011, Aracaju, SE. Anais do XXII SBIE - XVII WIE. Porto Alegre: SBC - Sociedade Brasileira de Computação, p. $1342-1351$

FIPA. (2012) Agent Communication Language Specifications. URL: <http://www.fipa.org/repository/aclspecs.html>.

JADE. (2012) Java Agent DEvelopment Framework. URL: <jade.tilab.com/>.

Moodle. (2012) A Free, Open Source Course Management System for Online Learning. URL: <http://www.moodle.org/>.

Okada, A. (2003) "Desafio para EaD. Como fazer Emergir a Colaboração e a Cooperação em Ambientes Virtuais de Aprendizagem?" Educação Online: teorias, práticas, legislação, formação corporativa. Edições Loyola, $2^{a}$ ed., São Paulo.

Perrenoud, P. (1999) “Construir as competências desde a escola”. Artmed, Porto Alegre, RS.

Protégé. (2012). The Ontology Editor. URL: < http://protege.stanford.edu/>.

Wooldridge, M. (2009) “An Introduction to Multiagent Systems”. Ed. Wiley, England, Second Edition. 